\title{
ANDANDO NA CORDA BAMBA? ANÁLISE DA FRAGILIDADE DA EMOÇÃO COMO VANTAGEM COMPETITIVA NA CRIAÇÃO DE VALOR DO CIRQUE DU SOLEIL
}

\author{
WALKING ON A TIGHTROPE? ANALYSING THE FRAGILITIES OF EMOTION AS A \\ COMPETITIVE ADVANTAGE IN CIRQUE DU SOLEIL'S CREATION OF VALUE.
}

CAMINAR POR LA CUERDA FLOJA? ANÁLISIS DE DEBILITAMIENTO DE LA EMOCIÓN COMO VENTAJA COMPETITIVA EN LA CREACIÓN DE VALOR DE CIRQUE DU SOLEIL.

\section{Felipe Cavalcante de Almeida}

Mestrando em Administração de empresas pela Universidade de Fortaleza - UNIFOR

E-mail: c felipecavalcante@yahoo.com.br (Brasil)

\section{Alyne Oliveira Vale}

Mestranda em Administração de empresas pela Universidade de Fortaleza - UNIFOR

E-mail: alynedovale@gmail.com (Brasil)

\section{Sérgio H. A. Cavalcante Forte}

Doutor em Administração pela Fundação Getúlio Vargas - FGV

Professor do Programa de Mestrado e Doutorado em Administração da Universidade de Fortaleza UNIFOR

E-mail: sergioforte@ unifor.br (Brasil) 
ANDANDO NA CORDA BAMBA? ANÁLISE DA FRAGILIDADE DA EMOÇÃO COMO

VANTAGEM COMPETITIVA NA CRIAÇÃO DE VALOR DO CIRQUE DU SOLEIL

\title{
RESUMO
}

Diversos aspectos positivos podem ser criados por meio de um relacionamento emocional entre empresa e consumidores, entretanto, a complexidade dos processos emocionais pode se tornar um desafio ao crescimento em longo prazo de empresas que busquem utilizar tal estratégia. Definiu-se, portanto, como objetivo, evidenciar possíveis fragilidades de estratégias organizacionais que buscam a criação de valor por meio de aspectos emocionais. Para isso foi realizado um estudo de caso na empresa canadense Cirque $d u$ Soleil, no qual a coleta de dados foi composta por uma entrevista com a chefe de relações-públicas da empresa e por outras entrevistas coletadas por meio de dados secundários; por uma imersão de três meses em um dos espetáculos da companhia; e pela coleta de dados secundários provenientes de mídias eletrônicas e impressas. A análise e a interpretação dos dados foram feitas por meio da técnica de análise de conteúdo. Percebeu-se que apesar do rápido crescimento e sucesso da empresa, existem certos desafios à continuidade do crescimento ligados com a consolidação de relações emocionais.

Palavras-chave: Estratégia; Vantagem Competitiva; Emoção; Cirque du Soleil.

\section{WALKING ON A TIGHTROPE? ANALYSING THE FRAGILITIES OF EMOTION AS A COMPETITIVE ADVANTAGE IN CIRQUE DU SOLEIL'S CREATION OF VALUE}

\begin{abstract}
Several positive aspects can be created through an emotional relationship between business and consumers. However, the complexity of the emotional processes can become a challenge to longterm growth of companies that seeks to use such strategy. Therefore, this study seeks to evidence possible fragilities of organizational strategies which create value through the emotional aspects. It was, then, conducted a case study in the Canadian company Cirque du Soleil, with the data collection consisting in an interview with the firm's head publicist and other interviews collected through secondary data, an immersion of three months in one of the company's shows and in secondary data from electronic and press medias. The data analysis and interpretation were done by using the content analysis technique. It was noticed that despite the rapid growth and success of the company there are certain challenges to the continued growth associated with the consolidation of emotional relationships.
\end{abstract}

Keywords: Strategy; Competitive Advantage; Emotion; Cirque du Soleil.

Revista Ibero-Americana de Estratégia - RIAE, São Paulo, v. 9, n. 1, p. 174-201, set./dez. 2010. 
Felipe Cavalcante de Almeida, Alyne Oliveira Vale \& Sérgio H. A. Cavalcante Forte

CAMINAR POR LA CUERDA FLOJA? ANÁLISIS DE DEBILITAMIENTO DE LA

EMOCIÓN COMO VENTAJA COMPETITIVA EN LA CREACIÓN DE VALOR DE

CIRQUE DU SOLEIL

\section{RESUMEN}

Varios aspectos positivos se pueden crear a través de una relación emocional entre las empresas y los consumidores, sin embargo, la complejidad de los procesos emocionales puede convertirse en un desafío para el crecimiento a largo plazo de las empresas que tratan de utilizar esta estrategia. Se definió por tanto, como objetivo relieve de las posibles deficiencias de las estrategias de organización que buscan crear valor a través de los aspectos emocionales. Para ello se realizó un estudio de caso en la compañía canadiense Cirque du Soleil, donde la recolección de datos consistió en una entrevista con el jefe de relaciones públicas de la firma e otras entrevistas recogidos a través de datos secundarios, una inmersión de tres meses en uno de los espectáculos de la compañía, y mediante la recopilación de datos secoundários de los medios de comunicación electrónicos e impresos. La analise e la interpretacion de los datos foram hechos a través de la técnica de análisis de contenido. Se observó que a pesar del rápido crecimiento y éxito de la empresa, existen ciertos desafíos para el crecimiento continuo asociado a la consolidación de las relaciones emocionales.

Palabras-clave: Estrategia; Ventaja Competitiva; Emoción; Cirque du Soleil.

Revista Ibero-Americana de Estratégia - RIAE, São Paulo, v. 9, n. 3, p. 174-201, set./dez. 2010. 
Andando na Corda Bamba? Análise da Fragilidade da Emoção como Vantagem Competitiva na Criação de Valor do Cirque du Soleil

\section{INTRODUÇÃO}

Muito se fala de estratégias para inovação e criação de valor para os produtos ou serviços das empresas, porém a competição cada vez mais acirrada exige que essa criação de valor acabe algumas vezes transpondo as capacidades e os recursos mais objetivos de uma organização. Em algumas visões estratégicas como a interpretativa e a construtivista, por exemplo, o que se encontra dentro da mente humana não é uma reprodução do mundo externo, uma vez que o fluxo de informações passa por filtros que, mediante a interação com a cognição, acabam moldando essas informações (Mintzberg, Ahlstrand \& Lampel, 2000).

Entretanto, uma vez que a criação de valor de uma empresa está baseada em um fator caracteristicamente subjetivo como a emoção humana, por exemplo, surgem problemas que estão relacionados com a difícil definição e mensuração, representando um estado subjetivamente inseparável de outras classes de informação psicológica (MacLean, 1993), gerando questionamentos sobre como devem as emoções específicas influenciar o julgamento e a escolha (Santos \& Prado, 2008), assim como, segundo Samara e Morsc (2005), pode também possuir um caráter frágil por causa da complexidade das emoções e do comportamento humano.

Dentre as empresas que parecem dar mais ênfase às estratégias de criação de valor baseada na emoção, a companhia circense canadense Cirque du Soleil talvez se apresente como uma das mais voltadas para a utilização desse modelo estratégico, utilizando-se de fatores como a performance de seus colaboradores (seja de seus artistas em palco ou do atendimento ao cliente) e de sua infraestrutura de ambiente, representando, assim, aspectos táticos para a realização da estratégia da empresa, voltada para o objetivo de atingir emocionalmente seus consumidores.

A análise do rápido crescimento da empresa nesses últimos 26 anos de existência gerou, contudo, o questionamento: estaria o Cirque du Soleil andando em uma corda bamba por empregar uma arriscada estratégia baseada na criação de valor emocional de seu produto? Este estudo tem como objetivo evidenciar possíveis fragilidades de estratégias organizacionais que buscam a vantagem competitiva empresarial na criação de valor por meio de aspectos emocionais. Mais especificamente, este artigo busca mesclar as teorias estratégicas de criação de valor e vantagem competitiva de Barney e Hersterley (2005); Hamel e Prahalad (1999); Kim e Maubourgne (2007) com teorias de renovação estratégica (Huy \& Constance, 2009), utilizando o caso da empresa Cirque du Soleil para exemplificar a possível existência de aspectos da cognição e emoção que podem representar tanto o sucesso de estratégias de criação de valor e vantagem competitiva como também fatores de fragilidade e desafios a longo prazo.

Revista Ibero-Americana de Estratégia - RIAE, São Paulo, v. 9, n. 1, p. 174-201, set./dez. 2010. 
Felipe Cavalcante de Almeida, Alyne Oliveira Vale \& Sérgio H. A. Cavalcante Forte

Assim, o estudo tem sua relevância graças à análise crítica pouco realizada na literatura de estratégia da criação de valor sustentada por aspectos emocionais, bem como em virtude da utilização de uma literatura baseada principalmente na intenção estratégica e inovação de Hamel e Prahalad (1999) e na estratégia de vantagem competitiva de Barney e Hersterly (2005) para exemplificar o caso da companhia Cirque du Soleil.

Inicialmente o artigo é composto pela realização de uma análise de dados secundários com o objetivo de levantar os aspectos teóricos sobre processos emocionais, vantagem competitiva e criação de valor, sendo seguido da metodologia de pesquisa, análise do caso, conclusão e referências.

\section{A CRIAÇÃO DE VALOR POR MEIO DA INOVAÇÃO}

Sabe-se que a extinção dos seres acontece pela ausência de adaptabilidade de forma suficientemente rápida (Hamel \& Prahalad, 1999). Desse modo, similarmente aos seres vivos, empresas, e até mesmo todo um setor, podem ser extintos em consequência da falta de adaptabilidade perante as rápidas mudanças ambientais, gerando assim uma pressão direcionada para a inovação e mudança organizacional (Hamel \& Prahalad, 1999).

Inovação, portanto, não deve se deter apenas em aumentar o valor percebido de seus produtos. Segundo Barney e Hersterley (2005), a inovação proporciona o ganho de vantagem competitiva com a alteração das características objetivas de produtos, entretanto é necessário gerar mudanças voltadas para a valorização da diversidade genética do capital humano (preferência na contratação de pessoas com experiências em diferentes áreas) e para a criação de uma organização desprendida do passado (voltada para o desaprendizado), a qual estaria disposta a deixar de lado parte do passado do setor e as convenções inquestionáveis, a visão míope das oportunidades e ameaças, e os precedentes não desafiados da estrutura gerencial (Hamel \& Prahalad, 1999).

Assim, tem-se a inovação como uma combinação e incorporação de elementos do conhecimento criando algo original, tendo sua relevância como produto, serviço ou processo (Luecke, 2003). Pode-se também, segundo Hussey (1997), ter a inovação como uma ação, podendo ser definida como uma ideia criativa a ser aplicada no ambiente organizacional. Outras diversas definições podem ainda ser citadas, por exemplo, a inovação como uma estratégia de adaptação organizacional no ambiente (Manu, 1992), vinculando sua adoção à implantação e ao desenvolvimento de novas ideias ou comportamento (V. I. Oliveira, 1997).

Revista Ibero-Americana de Estratégia - RIAE, São Paulo, v. 9, n. 3, p. 174-201, set./dez. 2010. 
Andando na Corda Bamba? Análise da Fragilidade da Emoção como Vantagem Competitiva na Criação de Valor do Cirque du Soleil

Para Vargas (2002), a inovação e a estratégia de uma empresa vão além da aplicação tecnológica, gerando uma relação direta entre as capacidades acumuladas e sua formulação estratégica e, consequentemente, sua capacidade de inovação. Em tal relação, ainda segundo esse autor, a inovação passa a ser dependente de um ambiente interno que venha a ser favorável ao aprendizado na organização, mas ao mesmo tempo também é dependente do ambiente externo que a circunda, gerando, segundo Giget (1997), uma necessidade de interação entre as várias funções que a compõem.

Dessa forma, uma vez que a inovação e a estratégia estão além da aplicação tecnológica, a criação de valor, segundo Castells (1999), acaba se tornando algo além da base tecnológica da empresa ou do auxílio no desenvolvimento de produto, sendo preciso assumir a participação dos clientes na criação de valor, deslocando a ideia de inovação para um centro de cocriação individual de experiências, de modo que, de acordo com Ramaswamy (2005), o universo do cliente se torne o centro.

Ramaswamy (2005) afirma ainda que ao se deslocar a criação de valor do centro da firma ou produto, busca-se alcançar uma interação significativa entre rede de firmas e comunidades que gere a possibilidade de uma personalização da experiência, de modo que o cliente possa cocriar sua própria experiência e determinar qual sua base de valor e, consequentemente, sua disposição em pagar.

Kim e Maubourgne (1999) destacam, porém, que existe um conceito de inovação de valor que se distingue do conceito de inovação tecnológica e do conceito estratégico de criação de valor, tendo o último se tornado muito amplo por não haver delimitações de condições específicas que possam direcionar uma empresa ao sucesso estratégico. Para esses autores, a inovação de valor é a conexão entre a inovação e o valor dado pela maioria dos consumidores, dessa forma, tem-se que produtos ou serviços superiores, por exemplo, devem manter preços compatíveis com poder de compra da maioria de seus clientes, caso contrário, possibilita-se que outras empresas possam realizar tal inovação e com preço acessível.

Em contraponto, ao mesmo tempo em que a inovação pode ser uma das melhores formas na busca de criação de valor, de acordo com Hall e Vredenburg (2003), ela também pode ser um elemento condutor de riscos e problemas futuros, os quais podem ser causados por oportunidades não visualizadas no decorrer do processo de inovação social, cultural e tecnológica que irá gerar uma nova concepção de valor na sociedade como um todo (Manzini \& Vezzoli, 2005). Assim, nesse novo contexto, é necessária a existência de uma cooperação que possibilite o aproveitamento das competências dos clientes e da administração de experiências personalizadas, moldando as 
Felipe Cavalcante de Almeida, Alyne Oliveira Vale \& Sérgio H. A. Cavalcante Forte

expectativas dos clientes em relação ao futuro, tanto para ensinar como para aprender com eles (Prahalad \& Ramaswamy 2000). Tem-se, então, o conceito de competências como uma possível vantagem competitiva, sendo ampliado para todo o sistema no qual a firma se encontra inserida (Moraes \& Manzini, 2009).

\section{A INTENÇÃO ESTRATÉGICA E A VANTAGEM COMPETITIVA MEDIANTE A RBV}

Segundo Hamel e Prahalad (1999), a intenção estratégica se caracteriza como o sonho que energiza e oferece a força emocional e intelectual para continuidade da jornada da empresa. Assim, por mais que no início a falta de recursos aponte para a necessidade de equilibrar e ajustar os recursos da empresa com as oportunidades emergentes, a intenção estratégica aponta para um desequilíbrio entre recursos e aspirações.

Entretanto, para a obtenção do sucesso da intenção estratégica de uma organização é necessário conseguir sucesso na transformação do sonho em realidade, algo que vai exigir dos funcionários o conhecimento exato de quão importante é sua contribuição para se chegar a essa realidade. Para tanto a organização precisa achar seu objetivo propulsor, além disso é necessário que os funcionários entendam como se estabelece a conexão entre seu próprio trabalho e a concretização das metas (Hamel \& Prahalad, 1999). O objetivo da intenção estratégica é colocar o futuro dentro do presente, buscando entender o que é possível fazer de diferente em um ano para se aproximar ainda mais dessa intenção, em vez de entender apenas o que será diferente nos anos posteriores. Assim, é mediante a articulação e a realização da intenção estratégica que se obtém uma vantagem competitiva a longo prazo.

Portanto, por meio da intenção estratégica pode existir também a possibilidade de combater o que Freedman e Tregoe (2003) chamam de curto-termismo (short-termism), o qual ocorre quando não existe um propósito central que consiga agrupar empregados, funções e unidades de negócios, permitindo-se também que os recursos sejam alocados de forma aleatória, que as mensurações sejam negligenciadas e, assim, comprometendo-se o futuro da organização. É um processo que gera um vácuo na organização, causado pelo enfraquecimento ou mesmo pela ausência de visão.

Hamel e Prahalad (1989) afirmam que a intenção estratégica permite um alongamento da organização, pois uma vez que os recursos e capacidades atuais não sejam suficientes, a empresa será forçada a inovar para conseguir os melhores resultados possíveis com seus recursos limitados. 
Dessa forma, ainda de acordo com esses autores, a intenção estratégica envolve um processo gerencial ativo que, dentre diversos aspectos, inclui sua utilização como direcionador da alocação de recursos.

Os recursos são também a questão-chave para a abordagem estratégica da Visão Baseada em Recursos (Resource Based View - RBV), a qual busca analisar como administrar os recursos tangíveis e intangíveis, a heterogeneidade das firmas e de que forma esses aspectos podem afetar a dinâmica setorial e criar vantagem competitiva sustentável para as organizações (Barney, 1991; Peteraf, 1993). Assim, segundo Barney (1991), uma vantagem competitiva sustentável é caracterizada quando uma empresa formula uma estratégia de criação de valor a qual não é implementada simultaneamente por concorrentes potenciais e que também não é apta a ter seus benefícios duplicados pelas demais empresas.

Segundo Barney e Hersterly (2005), uma vez que nem todos os recursos podem levar à vantagem competitiva, torna-se necessário que sejam identificados quatro atributos (VRIO), para que, então, venha a ser possível verificar o potencial de um recurso para gerar vantagem competitiva, são eles: valor (valuable) - melhorando a eficiência e eficácia da organização por meio da exploração de oportunidades e/ou neutralização das ameaças do ambiente; raro (rare) - seu caráter estratégico ocorre em virtude de sua raridade e alta demanda perante os recursos da competição corrente; imitável (inimitable) - deve ser de difícil imitação; organização (organization) - deve ter políticas e processos organizados para dar suporte à exploração de seus recursos valiosos, raros e custosos de imitar.

Segundo Rivera (2008), por meio das bases teóricas de Barney (1991), Prahalad e Hamel (1990) e Wernerfelt (1984), foi desenvolvido, então, um modelo definitivo de vantagem competitiva em RBV por Peteraf (1993), em que são analisadas quatro condições necessárias: heterogeneidade - fatores produtivos superiores escassos em relação à demanda e com ofertas limitadas; mobilidade imperfeita - recursos que não podem ser comercializados ou quando apresentam valor superior na empresa na qual foram originalmente empregados; limites à competição ex-ante - desempenho econômico depende tanto do retorno gerado como do custo de implementar a estratégia; e limites à competição ex-post - preservação da heterogeneidade para manutenção da vantagem competitiva sustentável ao longo do tempo; utilizando a RBV para explicar que diferenças duradouras de lucratividade não podem ser atribuídas apenas a diferenças setoriais.

Johnson (2009) afirma, contudo, que uma mudança particularmente importante está acontecendo no desenvolvimento estratégico, representando uma tendência de mudança das análises 
Felipe Cavalcante de Almeida, Alyne Oliveira Vale \& Sérgio H. A. Cavalcante Forte

de nível macro para análises de nível micro. Essa tendência cria uma preocupação com a relação que possa vir a se estabelecer entre os aspectos individuais dos consumidores, as empresas e suas estratégias, gerando, assim, uma preocupação com os resultados da interação entre essas partes. Ainda de acordo com esse autor, uma vez utilizando uma perspectiva psicológica, a interação coletiva, terá capacidade para revelar explicações acerca de fatores existentes, como a cognição e a emoção. Portanto, mediante a utilização desse discurso de interação coletiva no desenvolvimento da estratégia, a perspectiva psicológica torna possível também a análise de novos elementos estratégicos, como a emoção, afastando-se de representações enviesadas da cognição coletiva.

\section{OS FATORES EMOCIONAIS E A RENOVAÇÃO ESTRATÉGICA}

Existem diversas experiências que podem ser geradas pelas empresas, as quais ocorrem, segundo Moraes e Manzini (2009), quando uma empresa utiliza intencionalmente seus serviços como uma plataforma e os seus bens como propostas para engajar os clientes individualmente, buscando criar um evento que seja memorável. Por isso deve-se entender qual a verdadeira experiência a ser oferecida ao cliente (Lowendahl \& Revang, 1998), pois assim como os produtos e serviços, as experiências também devem estar direcionadas para o atendimento das necessidades dos consumidores (Moraes \& Manzini, 2009).

Estudos psicológicos recentes vêm buscando demonstrar a importância da cognição e da emoção em nível individual como fatores influenciadores da qualidade na tomada de decisão e no comportamento como cooperação ou negociação, entretanto, pouco ainda se sabe sobre como esses fatores cognitivos e emocionais podem influenciar importantes aspectos do processo de renovação estratégica, como o pensamento e o comportamento coletivo (Huy \& Constance, 2009). Para Weick e Roberts (1993), por exemplo, existia o receio de que essa nova perspectiva somente viesse a proporcionar insights organizacionais com respeito a um indivíduo de cada vez. Johnson (2009) afirma, contudo, que novos estudos gerenciais têm tratado de forma mais sofisticada essa noção de coletividade, acreditando-se que em alguns casos, de acordo com Larson e Christensen (1993), apesar de cada indivíduo ter sua visão de mundo, o entendimento da interação entre as pessoas é que cria essa visão coletiva.

Huy e Constance (2009, p. 1) definem a renovação estratégica como "um processo evolucionário que interrompe a inércia organizacional na tentativa de trazer mudanças nas competências organizacionais e na direção estratégica em resposta a um ambiente competitivo ou 
para a criação de um novo produto para ampliar a vantagem competitiva”. Existe, porém, a possibilidade da utilização e a persistência na renovação estratégica se tornarem difíceis para os gerentes (Burgelman, 1994), visto que sua utilização precipitada pode levar ao declínio, ou mesmo à falência da empresa, caso não seja administrada com competência, pois tem importantes consequências em fatores psicológicos e econômicos, assim como em emoções intensas como euforia, paixão, medo, raiva e frustração (Huy \& Constance, 2009).

Assim, mesmo sendo uma das variáveis que tem ganhado mais espaço nos estudos do comportamento de compra dos consumidores (Santos \& Prado, 2008), a emoção pode afetar o ato de compra de forma tal que pode chegar até mesmo a influenciar as avaliações que o consumidor fará do produto, independentemente da real qualidade que este possua (Mowen \& Minor, 2003). Considerando que a forma como os consumidores lidam com o estado emocional influencia em suas decisões de consumo (Santos \& Prado, 2008), a utilização de tal aspecto como sustentador da pirâmide de criação de valor de um produto ou serviço pode, assim, ser algo que gera uma intensa vantagem competitiva, porém, segundo Samara e Morsc (2005), pode também possuir um caráter frágil por causa da complexidade das experiências emocionais e do comportamento humano.

Tal complexidade está no fato, por exemplo, das experiências emocionais possuírem duas dimensões comuns (Fridja, 1986), a de valência e a de agitação. Para Detenber e Reeves (1996), valência pode ser definida como a dimensão emocional que pode estar relacionada tanto com um aspecto positivo como negativo, ou seja, uma contínua resposta afetiva que vai do prazer (valência positiva) ao desprazer (valência negativa). Segundo esses autores ainda, a agitação, por sua vez, pode ser definida como a dimensão emocional que estará relacionada com aspectos que vão da calma à euforia, os quais capturam a intensidade emocional como uma resposta contínua, envolvendo estados de impaciência, euforia e alerta até estados de calma, apatia e paz.

Tais dimensões emocionais, uma vez que compõem os consumidores, estão relacionadas às organizações as quais devem trabalhar a comunicação em sua estrutura social cautelosamente para não terem sua reputação ameaçada (Benoit, 1995). Isso porque uma vez que um erro estratégico ameace ou venha a ameaçar a reputação de uma organização é possível também que venha a causar fragilidade em outros aspectos empresariais como, por exemplo, a habilidade que esta possui em influenciar parceiros e consumidores.

Dessa forma, Gates (1995) afirma que quando uma empresa possui um produto bom, por exemplo, os investidores começam a prestar atenção e se dispõem a investir. Isso faz com que a imagem da empresa comece a ser consolidada e com que a mídia e o mercado falem sobre a empresa. Esse fato chama a atenção de jovens inteligentes, que começam a buscar uma vaga na 
Felipe Cavalcante de Almeida, Alyne Oliveira Vale \& Sérgio H. A. Cavalcante Forte

empresa. Assim, as pessoas que têm talento são atraídas para locais com pessoas de talento, o que gera uma sensação estimulante, criando emoções positivas e fazendo com que, cada vez mais, os colaboradores e clientes se sintam bem e continuem a espiral positiva de sucessos da empresa.

Por outro lado, ainda segundo Gates (1995), uma vez entregue ao cliente ou colaborador uma emoção ou uma experiência negativa, começa a se questionar tudo na empresa, até mesmo as coisas que estão sendo benfeitas. Dessa forma, acaba-se gerando uma espiral negativa de fracassos, podendo fazer até com que boas estratégias sejam malvistas em virtude de experiências anteriores, piorando cada vez mais a imagem da marca e da empresa perante os consumidores e colaboradores. Portanto, para sair de uma espiral negativa, a organização necessitará de uma estratégia cautelosa, evitando piorar ainda mais a situação em que se encontra.

Dessa forma, por meio de uma abordagem da psicologia cognitiva, têm-se as emoções tanto na esfera individual como em uma esfera social, gerando uma preocupação por meio dessa perspectiva cognitiva em criar uma relação entre os fatores emocionais, a cognição e os aspectos sociais (Daniel, Harris \& Briner, 2004). Contudo, ainda pouco se verifica essa preocupação dentro da atual perspectiva organizacional.

\section{METODOLOGIA DA PESQUISA}

Esta pesquisa configura-se como exploratória (Santos, 1991), mediante estudo de caso (Gil, 1999), por meio de pesquisa qualitativa (S. L. O. Oliveira, 1997; Vieira \& Zouain, 2006), sendo utilizada, além de dados secundários, dados primários com apoio de entrevista em profundidade semiestruturada (Duarte \& Barros, 2005).

Para a realização da pesquisa com dados primários na companhia Cirque du Soleil, foi feito contato em 2 de junho de 2009 para autorização da publicação do estudo e agendamento de entrevistas com a chefe de Relações-Públicas da turnê Quidam 2009. Apesar de única fonte de dado primário, outras entrevistas foram coletadas por meio de fontes de dados secundários, além disso, a entrevista foi relevante por ter sido realizada com a executiva de relações-públicas internacional da turnê Quidam, tendo sido buscados ainda dados de fontes secundárias, como, por exemplo, entrevistas em TV, rádio (on-line) e outras mídias impressas e eletrônicas. $\mathrm{O}$ estudo contou com um período de três meses de imersão na empresa, no qual um dos pesquisadores pôde verificar aspectos referentes ao treinamento e processos da organização.

Os questionamentos da entrevista foram enviados por e-mail para a empresa, a fim de serem apreciados pela diretoria, sendo aprovados em 9 de junho de 2009. A entrevista na empresa ocorreu 
dia 13 de junho de 2009, na sede do espetáculo Quidam do Cirque du Soleil, em Fortaleza, Ceará, da qual participou a Sra. M.J. (Chefe de Relações-Públicas do Cirque na turnê 2009 do espetáculo Quidam) que deu informações que possibilitaram o desenvolvimento deste estudo em respostas ao questionário formulado.

Para a análise e interpretação dos dados coletados foi aplicada a técnica de análise de conteúdo. Foi considerada uma análise de conteúdo por categorias, de forma a seguir a sequência metodológica de três etapas propostas por Bardin (1994): pré-análise, análise do material e o tratamento dos resultados. Para a decodificação dos textos foram analisadas as respostas por pergunta, ou seja, as unidades de análise envolvidas no estudo são os textos separados pelos temas (categorias) provenientes das entrevistas (Apêndice 1). Cada tema escolhido recebeu um código de identificação, e foi quantificado o número de vezes (unidades de registro) que cada tema apareceu em cada entrevista analisada.

Sobre as unidades de análises foi aplicada a forma de análise que trata as unidades por tema, a análise temática. Tal forma de análise foi escolhida pois, de acordo com Colauto e Beuren (2003, p. 138), ela permite "isolar os temas de um texto coletado e extrair as partes utilizáveis e correlacionáveis ao problema de pesquisa, para permitir a comparação com outros textos escolhidos do mesmo modo". Uma vez isolados os temas, buscou-se, por fim, compará-los com os dados primários e secundários coletados, procurando analisar conjuntamente os resultados das respostas.

\section{ESTUDO DE CASO}

\subsection{A HISTÓRIA DO CIRQUE DU SOLEIL}

Em 1982, um grupo de teatro de rua chamado Le Club des talons hauts (O Clube de sapatos de saltos altos) organizou nesse mesmo ano o La Fête Foraine, um evento cultural em que os artistas de rua de todos os locais se encontravam para trocar ideias e alegrar as ruas da cidade por alguns dias. $\mathrm{O}$ evento se repetiu durante os dois anos seguintes despertando um enorme sonho nos fundadores Guy Laliberté, Gilles Ste-Croix e em sua equipe: criar uma companhia circense em Quebec (Canadá) e levar essa companhia a se apresentar ao redor do mundo, buscando emocionar os espectadores durante o espetáculo.

$\mathrm{O}$ entendimento de que o mercado circense se encontrava em decadência inspirou seu fundador Guy Laliberté a buscar um novo conceito artístico. O objetivo era não competir no 
Felipe Cavalcante de Almeida, Alyne Oliveira Vale \& Sérgio H. A. Cavalcante Forte

mercado que anteriormente era voltado para as crianças, mas sim criar uma experiência de entretenimento que atingisse adultos frequentadores de teatro ou festivais de dança e arte, que estivessem dispostos a pagar mais por esse tipo de experiência nunca antes vivida (Kim \& Mauborgne, 2007).

Assim, para celebrar os 450 anos do descobrimento do Canadá por Jacques Cartier, Guy Laliberé apresentou, em 1984, uma proposta de show itinerante, chamado Cirque du Soleil (Circo do Sol), convencendo os organizadores da celebração pública.

O sucesso levou à continuidade do espetáculo, chegando a faturar em 2004, segundo Alonso (2005), cerca de U\$ 500 milhões por ano e ter sido assistido por 7 milhões de espectadores. Em 2009 o Cirque celebrou seus 25 anos de existência, com um novo show lançado em abril do mesmo ano em Montreal.

Já, em 2010, segundo Cameron e Nelson (2010), a empresa parece não ter conseguido atingir o sucesso esperado com o lançamento do espetáculo Banana Shpeel. O show, que deveria ter sido lançado em fevereiro de 2010 em Nova York (EUA.), teve a data adiada para abril do mesmo ano e foi levado para Chicago, onde não foi bem recebido pela audiência, que, pela primeira vez, parece não ter aprovado o misto de comédia, acrobacia e danças excêntricas presentes no espetáculo. Para Cameron e Nelson (2010), esse pode ser um primeiro sinal de algumas fragilidades que a empresa pode ter em razão do relacionamento emocional com seus clientes, o qual merece cautela para não gerar determinadas consequências negativas.

\subsection{A IMPORTÂNCIA DAS PESSOAS E DA INFRAESTRUTURA NA IMPLEMENTAÇÃO DA ESTRATÉGIA DA EMOÇÃO DO CIRQUE DU SOLEIL}

Neste tópico, analisam-se as questões que foram mais relevantes para explicar como a empresa Cirque du Soleil utiliza a emoção como fator estratégico na criação de valor, ou seja, trata de verificações realizadas no estudo por meio da análise de entrevistas por fontes primárias e secundárias que são relevantes para a afirmação da utilização de uma estratégia com base em fatores emocionais.

Assim, cabe destacar que, inicialmente, para atingir a intenção estratégica de criar uma companhia circense itinerante foi necessário que o Cirque du Soleil conquistasse não só o público de sua cidade ou país natal (Montreal, Canadá), mas sim os mais diversos públicos ao redor do mundo, um objetivo que enfrentaria o desafio das barreiras culturais. A ideia de realizar shows diferentes para cada local da turnê não poderia ser utilizada por causa, principalmente, do tempo 
Andando na Corda Bamba? Análise da Fragilidade da Emoção como Vantagem Competitiva na Criação de Valor do Cirque du Soleil

que levaria para realizar as adaptações necessárias (como tradução de músicas para a língua local, ou adaptação das piadas para a cultura local). Dessa forma, era necessário criar um padrão único para cada espetáculo, gerando o desafio de criar um espetáculo artístico que conseguisse atingir emocionalmente as pessoas de todas as culturas.

Por meio da análise das entrevistas (Apêndice 1), percebeu-se uma expressiva aparição de aspectos como a qualidade do desempenho humano por meio da emoção do colaborador, a qualidade do serviço como meio de gerar emoção no cliente e o suporte de infraestrutura para os efeitos de palco e para o espetáculo como um todo.

Uma das constatações desses fatores criados pelo estudo foi manifestada pela vicepresidente de Recursos-Humanos da empresa, em entrevista ao canal IDEAL TV (2009). Quando indagada sobre a diferença em ser uma executiva de RH no Cirque du Soleil e em uma executiva de RH em outra grande empresa, ela afirmou:

No Cirque as pessoas se sentem atraídas pela organização por paixão. Eles têm paixão pelo seu trabalho. Eles têm paixão por algumas coisas por vezes fora do trabalho. São pessoas muito interessadas pelo mundo do entretenimento [...] Para o Cirque a paixão é a força motriz. Ela é muito importante em nossa avaliação.

Ainda relacionado ao aspecto emocional no ambiente de trabalho, por sua vez, quando um dos pesquisadores perguntou à chefe de Relações-Públicas do Cirque como que o time de funcionários do Cirque contribuía para a criação de valor durante o consumo, ela afirmou que:

Todos têm de comprar a ideia do que somos como uma empresa [...] eles fazem o que fazem porque são apaixonados por ela. As pessoas aqui têm paixão pelo que fazem, caso contrário, eles não vivem em casa. Nós temos pessoas neste espetáculo que estão conosco há 10 até há 14 anos já. Assim, elas não foram para casa muitas vezes. Esta turnê em particular já está na nossa décima sétima cidade e no vigésimo primeiro país. Há alguns artistas que trabalharam em todos esses lugares. Então, você tem que amar o que você faz para ficar por tanto tempo! Todo mundo quer se levantar, você não sente as pessoas cansadas muitas vezes por aqui. Principalmente nesta região do Brasil, que é como uma top 5 das regiões mais pobres que já fomos. Por isso tentamos dar o melhor que podemos todos os dias, para que o nosso público possa sentir a nossa magia.

Revista Ibero-Americana de Estratégia - RIAE, São Paulo, v. 9, n. 1, p. 174-201, set./dez. 2010. 
Felipe Cavalcante de Almeida, Alyne Oliveira Vale \& Sérgio H. A. Cavalcante Forte

Percebe-se, por meio desses dois parágrafos em entrevistas diferentes, uma convergência com relação à importância dada às pessoas. Essa importância parece ter gerado uma nova concepção de experiência de entretenimento gerando características propícias à criação de valor para o serviço e para a marca. Por meio dessa nova concepção, passou-se a tratar seu público não apenas como espectadores, mas como amantes do teatro, música e arte, criando, assim, os conceitos que serviriam de base para essa inovação de produto, como: a retirada de animais (o que reduziu os custos de transporte e acabou com os problemas de legalização); diferentes produções realizadas ao mesmo tempo, cada uma com seu próprio tema; músicas originais e apresentadas ao vivo para cada show; criação de um aspecto mais refinado de palhaço; criação de vestuários diferentes e maquiagens originais na tentativa de eternizar o personagem e não o artista (o que reduzia os custos de contratação de astros circenses); preocupação com a estrutura (ambientação do picadeiro, valorização de temas inovadores, efeitos de iluminação e cenários de palco) (Figura 1), que evocassem emoções profundas durante os espetáculos (Kim \& Mauborgne, 2007), foram aplicados.

Figura 1 - Matriz de Avaliação de valor do Cirque du Soleil.

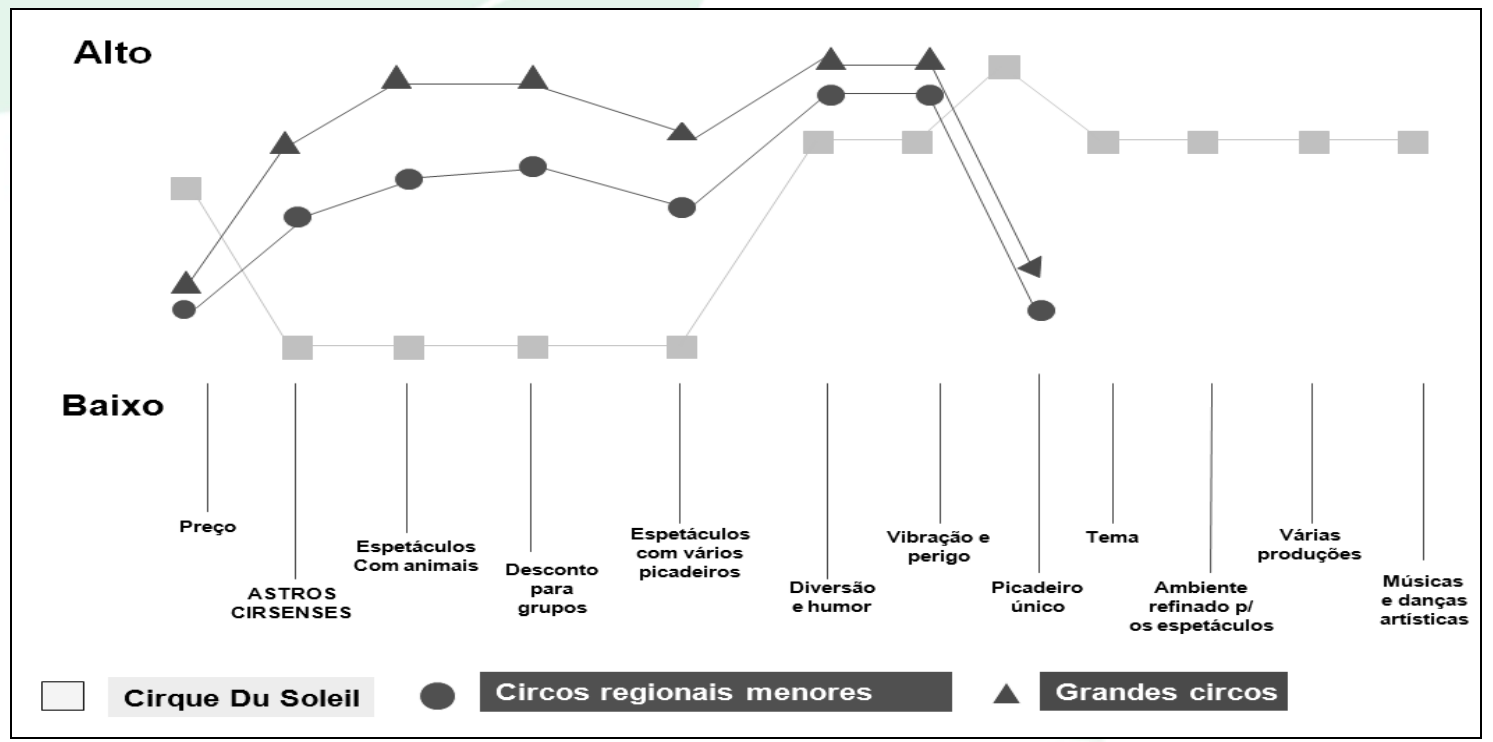

Fonte: Kim \& Maubourgne (2007, p. 40).

Percebeu-se, então, que a qualidade do serviço estava intrinsecamente relacionada com o suporte na produção dos shows, por isso foi caracterizado como o outro fator principal na criação de valor e atingimento emocional juntamente com a qualidade do desempenho humano. De acordo com Fagundes (2008), algumas produções chegam a atingir os US\$ 165 milhões, mais do que todos os espetáculos produzidos na Broadway, em Nova York, juntos, em 2007. Esse investimento busca 
a criação de novos efeitos de iluminação, equipamentos e máquinas para utilização no show, efeitos pirotécnicos, ambientação, entre outros, tudo isso para criar o mundo mágico de cada espetáculo. No espetáculo $K A$, por exemplo, o palco consiste em sete minipalcos, alguns dos quais são controlados por braços hidráulicos, incluindo o palco principal que possui 8 metros de altura por 16 metros de comprimento, e pode atingir um ângulo de $0^{\circ}$ a $90^{\circ}$ verticalmente e girar $360^{\circ}$ horizontalmente (Figura 2).

Por outro lado, a qualidade do serviço não se restringe aos palcos. Outras preocupações e detalhes podem ser percebidos, alguns mais evidentes outros nem tanto. Durante o período de imersão de um dos pesquisadores, foram verificados detalhes na engenharia, arquitetura e decoração que, direta ou indiretamente, buscavam atingir emocionalmente os espectadores. Assim, detalhes como a climatização das tendas, cadeiras acolchoadas, ou mesmo ações de bastidores que acontecem de forma proposital, buscam manter o ambiente mágico do espetáculo, de forma tal que existem momentos no palco em que os responsáveis pelos bastidores possuem a instrução de realizar os chamados lockouts, que consistem em cortinas negras fixadas nas portas de entrada da tenda do espetáculo, que bloqueiam qualquer luz externa. Nesses momentos todos os clientes que estão do lado de fora do show são impedidos de entrar na tenda principal, até que acabe o ato e se inicie outro, isso porque para eles é necessário que o espectador entre no mundo do show, só devendo ser incomodado por motivos especiais.

A área do Tapis Rouge (área VIP) é outro exemplo da preocupação com a infraestrutura e ambientação. Nessa área encontram-se objetos decorativos, como tapetes vermelhos (que buscam dar o tom de importância dos clientes que lá se encontram), projeções de vídeos em armações circulares de tecido suspensas no ar, com cerca de 6 metros de diâmetro, área reservada para compra de produtos, banheiros reservados, serviço open bar e de canapés e sobremesas, serviço de host e hostess para tirar dúvidas e acompanhar os clientes, mesas decoradas, entre outros elementos (Figura 3) que buscam estender a emoção do palco para outros ambientes durante o intervalo do show. 
Felipe Cavalcante de Almeida, Alyne Oliveira Vale \& Sérgio H. A. Cavalcante Forte

Figura 2 - a. Palco hidráulico do espetáculo KÀ.

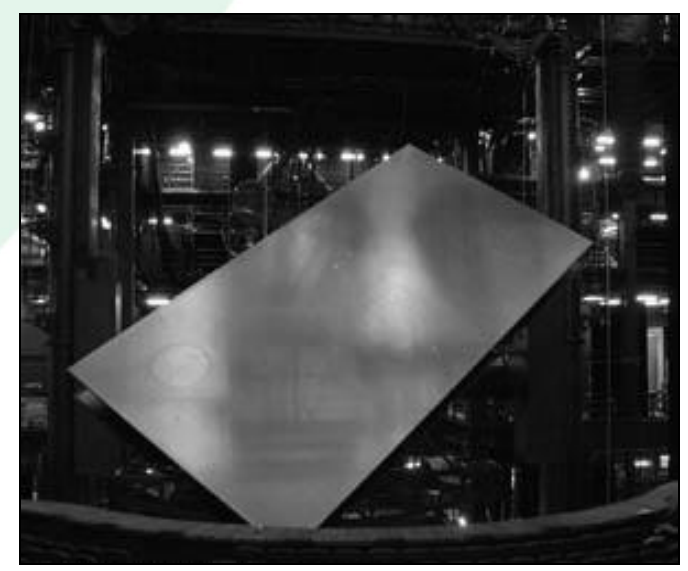

Fonte: http://www.tisfoon.com/cirquedusoleilka.html

Figura 3 - Ambiente Tapis Rouge (área VIP).

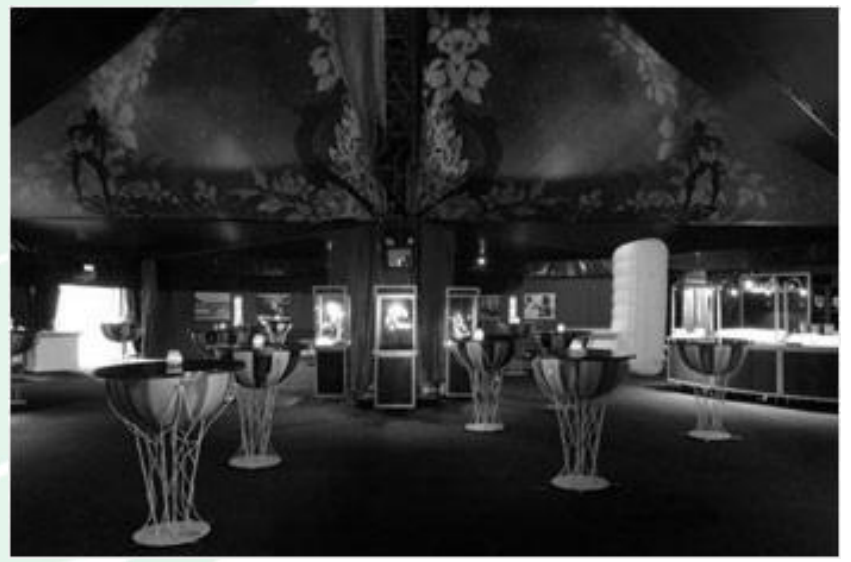

Fonte: www.cirquedusoleil.com

Contudo, apesar da importância do aspecto de infraestrutura, a análise das entrevistas evidenciou que a qualidade do serviço é um aspecto emocional que também está estritamente relacionado com a qualidade do desempenho humano. Tal evidência foi notada quando se questionou a chefe de Relações-Públicas do Cirque sobre os processos emocionais mais importantes para a empresa. Ela afirmou que:

No Cirque nós sempre começamos pelas pessoas, porque aqui tudo começa a partir de uma pessoa. Assim, nós temos diretores e artistas que cuidam do desempenho do show, assim como temos pessoas que trabalham nos bastidores para se certificarem de que tudo está ok. E assim as pessoas vão gostar e voltar. Mas, quando pensamos nas pessoas como clientes, nós gostamos de

Revista Ibero-Americana de Estratégia - RIAE, São Paulo, v. 9, n. 3, p. 174-201, set./dez. 2010. 
Andando na Corda Bamba? Análise da Fragilidade da Emoção como Vantagem Competitiva na Criação de Valor do Cirque du Soleil

ter certeza de que tudo que podíamos fazer para que elas tivessem a experiência do Cirque tenha sido feito, desde o primeiro momento quando a pessoa andar por nosso estacionamento.

Contudo, considerando que, segundo Barney e Hesterly (2005), todos os setores assumiram um caráter mais internacional nos últimos anos, tem-se que a competição internacional acaba gerando efeitos sobre o nível e os tipos de oportunidades de um setor específico, ampliando também as ameaças externas que uma empresa possa vir a ter. Por isso, apesar das características de criação de valor elaboradas pela empresa, o Cirque du Soleil como uma companhia itinerante mundial possui uma complexa tarefa relacionada com enfrentamento de todas as barreiras entrantes. Por meio da observação participante, notou-se que a infraestrutura também passa a envolver os aspectos logísticos, buscando solucionar o impasse entre a inovação do serviço - composta por um enorme fluxo de pessoas e equipamentos - e a viabilidade logística. Foram geradas soluções com a inovação do processo logístico, dentre as quais foi possível observar desde o prático design de cenários, equipamentos, stands, banheiros, cadeiras, mesas, entre outros elementos (dentro e fora dos palcos) que fossem rapidamente desmontáveis até o complexo misto de meios de transporte, permitindo a rápida mobilidade da empresa entre os mais diversos países do mundo.

Assim, a forte interação entre os fatores de inovação na qualidade do serviço (envolvendo tanto o fator da infraestrutura como o foco no desenvolvimento das capacidades humanas) e a qualidade do desempenho de seus funcionários (seja na ênfase da qualidade de serviço prestado, seja no desempenho dos artistas) foram, possivelmente, os fatores mais importantes para o sucesso mundial do Cirque du Soleil e, consequentemente, para o sucesso em atingir o sonho da empresa de ser uma companhia itinerante.

Contudo, um importante aspecto deve ser analisado, pois a inovação da companhia parece ter se tornado algo intrínseco não apenas à empresa como um todo, mas como algo que o público de todos os locais no mundo espera a cada espetáculo. $\mathrm{O}$ estudo buscou a hipótese em que os espetáculos da companhia tornaram-se, assim, possivelmente sustentados pelo padrão como conseguem atingir emocionalmente o público e que se tornou fixo na mente dos clientes da empresa. Dessa forma, a relação emocional também parece ter gerado uma alta expectativa nos consumidores de superação dos espetáculos anteriores. Assim, uma vez que se considera a utilização de uma estratégia que tem como base de sua vantagem competitiva o aspecto emocional, deve-se considerar não apenas a intensidade e a velocidade com que tal estratégia pode proporcionar o sucesso da empresa, mas também devem-se considerar quais os possíveis impactos que se pode obter, uma vez que se torne cada vez mais difícil superar a expectativa do cliente e dar

Revista Ibero-Americana de Estratégia - RIAE, São Paulo, v. 9, n. 1, p. 174-201, set./dez. 2010. 
Felipe Cavalcante de Almeida, Alyne Oliveira Vale \& Sérgio H. A. Cavalcante Forte

continuidade à raridade e à imitabilidade de um produto baseado em um aspecto tão subjetivo quanto a emoção.

\subsection{A SUSTENTAÇÃO DA PIRÂMIDE DE CRIAÇÃO DE VALOR NA EMOÇÃO: A INTENSIDADE E FRAGILIDADE DA EMOÇÃO COMO BASE DA VANTAGEM COMPETITIVA}

Neste tópico, buscou-se verificar as questões mais relevantes que sustentam a hipótese de que os espetáculos da companhia são possivelmente sustentados pelo padrão com o qual conseguem atingir emocionalmente o público e que se tornou fixo na mente dos clientes da empresa. Esses fatores foram provenientes da expressiva aparição dos temas de padrão de serviço e inovação (Apêndice 1), os quais foram relacionados no estudo como possíveis fragilidades por causa da geração de expectativa, fixação de percepção de padrão de serviço e barreiras de inovação.

De acordo com a literatura estratégica, seja para sair do Oceano Vermelho de alta competição de Kim e Mauborgne (2007), seja para atingir a intenção estratégica da empresa de acordo com Hamel e Prahalad (1999), a utilização de uma vantagem competitiva virá sempre a ter um importante papel na estratégia da empresa, principalmente, segundo Barney e Hesterly (2005), quando uma empresa se utiliza da visão baseada em recursos e do modelo VRIO, permitindo saber quão sustentáveis serão essas vantagens e quais serão as fontes dessas vantagens competitivas.

Entretanto, em meio à rápida reprodução tecnológica, muitas empresas acabam buscando na criação de valor um aspecto mais intangível e subjetivo, que possa ser valioso, raro, imitável a curto prazo e que possa ser explorado pela organização. Essa estratégia de criação de valor por meio de recursos intangíveis pode adentrar na esfera emocional, como no caso da companhia Cirque Du Soleil.

Utilizando-se dos fatores identificados como principais ferramentas para o atingimento emocional na estratégia do Cirque (percepção do discurso de preocupação com a qualidade do serviço e do desempenho humano, juntamente com a importância da ambientação), verificou-se, também, por meio da fala da Chefe de Relações-Públicas do Cirque a importância da convergência desses fatores para proporcionar uma experiência emocional positiva nos clientes:

Um dos nossos slogans é evocar, invocar e provocar. Assim, invocar sua imaginação, evocar os seus sentidos e provocar sua emoção. Isso resumidamente mostra o que fazemos. Assim, com relação à experiência quando as pessoas vierem ver nosso show, é isso que queremos emocionalmente, o que queremos que eles sintam quando eles saem do nosso show.

Revista Ibero-Americana de Estratégia - RIAE, São Paulo, v. 9, n. 3, p. 174-201, set./dez. 2010. 
Andando na Corda Bamba? Análise da Fragilidade da Emoção como Vantagem Competitiva na Criação de Valor do Cirque du Soleil

Contudo, a criação da hipótese de sustentação do sucesso dos espetáculos em virtude da criação de um padrão fixo de atingimento emocional, possibilitou assim a percepção de uma possível fragilidade no estabelecimento a longo prazo dessa estratégia. Isso porque o modelo de constante inovação criado pela empresa para atingir emocionalmente o cliente possibilita também a geração de uma alta expectativa, esperando que cada novo espetáculo seja melhor que o anterior em atingir suas emoções.

Tal fato foi verificado na pesquisa quando analisados os dados relacionados com um recente espetáculo da empresa que não foi bem-aceito pelo público. Tal espetáculo buscou inovar por meio de um novo padrão de espetáculo que tinha como intuito competir artisticamente e comercialmente com espetáculos da Broadway, inserindo diversos elementos do gênero teatral de vaudeville no espetáculo, mas que acabou, segundo Healy (2010), se tornado uma das maiores frustrações da empresa. Para Nelson (2010), em entrevista ao Canadian Business Podcast, a inovação do Cirque $d u$ Soleil está começando a se tornar mais uma regra do que uma exceção, o que de certa forma leva a empresa a um certo momento de risco. Percebe-se aí uma primeira evidência de que o formato de inovação como meio de atingir o consumidor pode se tornar uma barreira a longo prazo dada a dificuldade de superação constante da expectativa dos clientes.

Ainda analisando esse espetáculo em particular, Nelson (2010) afirma que a má aceitação do recente espetáculo aconteceu porque se criou um padrão de produto que consolidou uma relação emocional entre os consumidores, os espetáculos da empresa e, consequentemente, com a marca, de forma que os consumidores acabaram se tornando controladores, não aceitando qualquer mudança nesse padrão.

Em entrevista a Healy (2010), o presidente e chefe executivo do Cirque du Soleil disse que essa era a primeira vez que a empresa tinha cancelado permanentemente um espetáculo de forma tão rápida e que não poderia dizer se existiria a possibilidade do Cirque tentar algo tão teatralmente direcionado novamente. Ele ainda afirmou: "Nós tentamos algo muito novo e muito diferente para o Cirque, que é o que amamos fazer - enfrentar novos desafios criativos - mas obviamente este foi um processo difícil e de certa forma surpreendente para nós". Novamente, percebe-se a sustentação da hipótese de criação de um padrão fixo na mente dos consumidores como forma de sustentação do sucesso dos espetáculos.

O problema, porém, não se restringe à possibilidade de atingir as emoções apenas, mas também em como mensurá-las, uma vez que, segundo Oatley e Jenkins (1996), existem relativamente poucas evidências observadas de emoções sendo causadas por eventos que podem ser objetivamente classificados, pelo fato de essas evidências serem frequentemente episódios passados 
Felipe Cavalcante de Almeida, Alyne Oliveira Vale \& Sérgio H. A. Cavalcante Forte

ou sobre histórias prototípicas. Além disso, existe também o fato das emoções estarem associadas com outros estados psicológicos, que também são de difícil definição e mensuração, representando um estado subjetivamente inseparável de outras classes de informação psicológica (Maclean, 1993), gerando questionamentos sobre como devem as emoções específicas influenciar o julgamento e a escolha (Santos \& Prado, 2008).

Assim, apesar da importância de buscar uma criação de valor de um produto ou serviço como base no aspecto emocional (buscando gerar laços afetivos entre a empresa e os consumidores), uma vantagem competitiva proveniente desse tipo de estratégia de criação de valor também vai estar relacionada com o problema da fragilidade dos laços emocionais em virtude da volatilidade dos aspectos psicológicos e de sua complexidade, assim como estará também relacionada com o problema do seu controle e mensuração.

O próprio presidente e chefe executivo do Cirque du Soleil, em entrevista a Healy (2010), afirma ainda que: "quando se está trabalhando em um espetáculo que se espera que seja diferente das outras produções por aí afora, é possível adentrar em problemas como os das pessoas tentando definir o que o show é”. Ainda por meio da análise da entrevista a Healy (2010), o fundador e diretor artístico da empresa Big Apple Circus, que compete em Nova York com o Cirque du Soleil, também evidenciou a dificuldade em mudar o padrão já estabelecido pelo Cirque:

A realidade é que as pessoas têm expectativas bastante específicas com relação aos espetáculos do Cirque, de forma que o espetáculo acabou não sendo nem um ato circense e nem um espetáculo teatral vaudeville. Assim, se tornou difícil afetar a audiência com um show em que ela nem conseguia entender direito do que se tratava.

A análise dessa afirmação permitiu tanto evidenciar ainda mais a hipótese de criação de um padrão de espetáculo fixo como forma de atingir emocionalmente o cliente, como também levou à evidência de um problema relacionado com o controle e mensuração de um fator tão subjetivo como é a emoção.

Dado o interesse em saber sobre os métodos de mensuração da experiência e emoção do consumidor, a chefe de Relações-Públicas do Cirque disse que tipos de ferramentas eram utilizadas para esse tipo de mensuração emocional. Segundo ela:

Às vezes nós também recebemos mensagens de pessoas que vêm para ver o nosso show, e elas comentam sobre a experiência que viveram, sobre como nós as fizemos sonhar de duas horas etc. Temos também um livro na bilheteria em que o cliente pode escrever seus comentários, positivos 
Andando na Corda Bamba? Análise da Fragilidade da Emoção como Vantagem Competitiva na Criação de Valor do Cirque du Soleil

ou negativos, e nós lemos e respondemos a todos. Os clientes podem enviar os seus comentários através do site também, mas todos esses comentários vão primeiro para Montreal e eles enviam de volta para os funcionários nas turnês. Dessa forma, eu recebo alguns comentários de clientes e da mídia, porque estou em turnê, e por isso sei de alguns detalhes que eles não sabem em Montreal.

Nota-se que, apesar da preocupação com a experiência emocional do cliente, a empresa não parece contar com nenhuma forma objetiva de mensuração dessa experiência. Entretanto, como poderia o Cirque du Soleil comparar o impacto do uso e do não uso do efeito emocional nos custos e receitas da empresa, uma vez que não se consegue objetivar a emoção?

Parece ser possível, então, que a companhia canadense possa vir a realmente caminhar na corda bamba, pois mesmo merecendo aplausos pelo mérito de seus feitos na indústria do entretenimento mundial no mundo dos negócios como um todo, também pode deixar preocupado aquele que analisar de forma mais profunda não somente quão intensamente positiva pode ser uma relação entre empresa e consumidor baseada na emoção, mas também o quão frágil essa relação pode ser dada a complexidade da criação de valor segundo um aspecto psicológico tão complexo e subjetivo.

Entretanto, a empresa parece estar otimista com seus planos e sua estratégia, podendo ter levado a empresa a entender mais sobre seus clientes e o aspecto emocional, uma vez que, segundo o próprio presidente e chefe executivo da empresa: "Nós não nos achamos invencíveis, não éramos arrogantes sobre o espetáculo. Mas o espírito do Cirque, trabalhando noite e dia para o show dar certo, é um ponto de orgulho para nós, e queremos dar a oportunidade para nossa equipe concertar o show".

\section{CONCLUSÃO}

Com esse estudo buscou-se mostrar que a sustentação da criação de valor de um produto ou serviço baseado em complexos fatores, como o aspecto emocional humano, ao mesmo tempo em que pode ser um fator de sucesso, também pode ser algo arriscado e frágil em uma estratégia de criação de valor utilizada por uma empresa. No caso da companhia Cirque du Soleil, apesar desse aspecto emocional aparentar ser um dos fatores mais importantes para a empresa, tendo possivelmente sido uma das principais ferramentas para atingir a intenção estratégica de uma 
Felipe Cavalcante de Almeida, Alyne Oliveira Vale \& Sérgio H. A. Cavalcante Forte

companhia circense itinerante de sucesso mundial, a sustentação da criação de valor e a geração de uma vantagem competitiva baseada na emoção (seja pela qualidade do trabalho das pessoas dentro e fora dos palcos, seja pela inovação na sua infraestrutura) também pode ter levado à geração de uma expectativa muito alta com relação à superação de cada novo show sobre os antigos. Além disso, é possível também que essa abordagem emocional tenha fixado uma relação entre os consumidores do Cirque e um determinado padrão de espetáculo com características específicas que, caso venham a ser alteradas (caso do espetáculo Banana Shpeel), não tornará esse show bem-aceito pelos seus consumidores, independentemente da qualidade da produção.

Assim, reconhecendo a importância do uso de aspectos emocionais como geradores de vantagem competitiva e criação de valor, também se deve reconhecer que seus usos ainda abrangem riscos relacionados com a dificuldade de mensuração de aspectos subjetivos e psicológicos, assim como relacionados com a dificuldade de compreensão e de variabilidade dos aspectos que podem causar os diversos estados emocionais nos consumidores.

O estudo, porém, apresenta limitações relacionadas ao fato da pesquisa qualitativa ter sido realizada em junho de 2009 (meses antes do lançamento do espetáculo Banana Shpeel) e ter contado apenas com uma representante da companhia. Entretanto, a entrevista foi relevante por ter sido feita com a chefe de relações-públicas internacional da turnê Quidam, tendo sido buscados ainda dados de fontes secundárias, como, por exemplo, entrevistas em TV, rádio (on-line) e outras mídias impressas e eletrônicas, além da vivência de um dos pesquisadores no apoio de um dos espetáculos da empresa durante três meses e em cada mês passou por uma função diferente, iniciando no atendimento ao cliente dentro da tenda do show, passando para assistência de coordenação de atendimento ao cliente e depois para o atendimento ao cliente na área VIP (TapisRouge).

Outras possíveis pesquisas com caráter qualitativo ou quantitativo com os consumidores da companhia Cirque du Soleil poderiam analisar o problema pela perspectiva do cliente, dando suporte ou contrariando a hipótese aqui criada de que a criação de valor baseada em aspectos emocionais pode gerar problemas por causa da fragilidade na relação emocional com o cliente, a possibilidade de geração de uma alta expectativa por inovações superiores constantes e a dificuldade de compreensão dos aspectos que causam os estados emocionais nos consumidores.

Revista Ibero-Americana de Estratégia - RIAE, São Paulo, v. 9, n. 3, p. 174-201, set./dez. 2010. 
Andando na Corda Bamba? Análise da Fragilidade da Emoção como Vantagem Competitiva na Criação de Valor do Cirque du Soleil

\section{REFERÊNCIAS}

Alonso, V. (2005). A magia do Cirque du Soleil. HSM Management, 9(5)2, 1-7.

Bardin, L. (1994). Análise de conteúdo. Lisboa: Edições 70.

Barney, J. B. (1991). Firm resource and sustained competitive advantage. Journal of Management, 17(1), 99-120. http://dx.doi.org/10.1177/014920639101700108

Barney, J. B., \& Hersterly, W. S. (2005). Administração estratégica e vantagem competitiva. São Paulo: Pearson Prentice Hall.

Benoit, W. L. (1995). Sears' repair of its auto service image: Image restoration discourse in the corporate sector. Communication Studies, 46, 89-105

Burgelman, R. A. (1994). Fading memories: a process theory of strategic business exit in dynamic environments. Administrative Science Quarterly, 39(1), 24-56.

http://dx.doi.org/10.2307/2393493

Cameron, L., \& Nelson, J. (2010). Cirque's mid-life crisis. Recuperado em 12 de junho, 2010, de http://ca.finance.yahoo.com/personalfinance/article/ canadianbusiness/1562/cirques-mid-lifecrisis.

Castells, M. (1999). A sociedade em rede. São Paulo: Paz e Terra.

Colauto, R. D.; Beuren, I. M. (2003). Coleta, análise e interpretação dos dados. In I. M. Beuren (Coord.), Como elaborar trabalhos monográficos em contabilidade: teoria e prática (pp. 118144). São Paulo: Atlas.

Daniels, K., Harris, C., \& Briner, R. B. (2004). Linking work conditions to unpleasant affect: cognition, categorisation and goals. Journal of Occupational and Organizational Psychology, 77, 343-364.

Detenber, B. H., \& Reeves, B. (1996). A bio-informational theory of emotion: motion and image size effects on viewers. Journal of Communication, 46(3), 66-84.

Duarte, J., \& Barros, A. (Orgs). (2005). Entrevista em profundidade: métodos e técnicas de pesquisa em comunicação. São Paulo, Atlas.

Fagundes, L. (2008). Cirque du Soleil: aula de empreendedorismo e inovação. Recuperado em 10 de junho, 2010, de http://www.catho.com.br/jcs/inputer_view.phtml?id=9208. 
Felipe Cavalcante de Almeida, Alyne Oliveira Vale \& Sérgio H. A. Cavalcante Forte

Freedman, M., \& Tregoe, B. B. (2003). The art and discipline of strategic leadership. New York: McGraw-Hill.

Frijda, N. H. (1986). The emotions. London: Cambridge University Press.

Gates, B. (1995). A Estrada do futuro. São Paulo: Companhia das Letras.

Giget, M. (1997). Technology, innovation and strategy: recent developments. International Journal of Technology Management, 14(6/7/8), 613-634.

Gil, A. C. (1999). Métodos e técnicas de pesquisa social (5a ed.) São Paulo: Atlas.

Hall, J., \& Vredenburg, H. (2003). The challenges of innovating for sustainable development. MIT Sloan Management Review, 45(1), 61-68.

Hamel, G., \& Prahalad, C. K. (1999). Competindo pelo futuro. Rio de Janeiro: Campus.

Hamel, G., \& Prahalad, C. K. (1989). Strategic intent. Harvard Business Review, 67(3), 63-78.

Healy, P. (2010, May 26). How cirque slipped on 'shpeel'. New York Times, p. 1.

Hussey, D. E. (1997). Creativity, innovation and strategy. In D. E. Hussey (Ed.), The innovation challenge (pp. 1-15). Chichester: JohnWiley \& Sons.

Huy, Q. N., \& Constance, B. (2009). Interaction between cognition and emotion on processes of strategic renewal. Chicago: Academy of Management.

Ideal Tv. (2009). Programa siga o mestre. Recuperado em 14 junho, 2010, de http://www.youtube.com/watch?v=KH3fxILjG5g\&feature=related.

Johnson, P. (2009). Swapping collective cognition for experienced collectivity in the strategicmanagement literature. International Studies of Management \& Organization, 39(1), 34-49. http://dx.doi.org/10.2753/IMO0020-8825390102

Kim, W. C., \& Mauborgne, R. (2007). A estratégia do oceano azul: como criar novos mercados e tornar a concorrência irrelevante (19a ed.). Rio de Janeiro: Elsevier.

Kim, W. C., \& Maubourgne, R. (1999). Strategy, value innovation, and the knowledge economy. Sloan Management Review, 40(3), 41-54. 
Larson, J. R., \& Christensen, C. (1993). Groups as problem solving units: toward a new meaning of social cognition. British Journal of Social Psychology, 32(1), 5-30.

Lowendahl, B., \& Revang, O. (1998). Challenges to existing strategy theory in a postindustrial society. Strategic Management Journal, 19(8), 755-773. http://dx.doi.org/10.1002/(SICI)1097-0266(199808)19:8<755::AID-SMJ968>3.3.CO;2-1 http://dx.doi.org/10.1002/(SICI)1097-0266(199808)19:8<755::AID-SMJ968>3.0.CO;2-A

Luecke, R., \& Katz. R. (2003). Managing creativity and innovation. Boston: Harvard Business School Press.

MacLean, P. D. (1993). Cerebral evolution of the emotion. In M. Lewis \& J. M. Haviland-Jones (Eds.), Handbook of emotions (pp. 67-83). New York: Guilford Press.

Manu, F. A. (1992). Innovation orientation, environment and performance: a comparison of U.S and European markets. Journal of International Business Studies, 23(2), 333-359.

http://dx.doi.org/10.1057/palgrave.jibs.8490271

Manzini, E., \& Vezzoli, C. (2005). O desenvolvimento de produtos sustentáveis (A. Carvalho, Trad.). São Paulo: Universidade de São Paulo.

Mintzberg, H., Ahlstrand, B., \& Lampel, J. (2000). Safári da estratégia: um roteiro pela selva do planejamento estratégico (N. Montigelli Junior, Trad.). Porto Alegre: Bookman.

Moraes, E. A., \& Manzini, R. B. (2009). A co-criação de valor através das experiências: uma pesquisa nas empresas do estado de São Paulo [CD-ROM]. Anais do Encontro de Estudos em Estratégia, 4. Rio de Janeiro: ANPAD.

Mowen, J. C., \& Minor, M. S. (2003). Comportamento do consumidor. São Paulo: Prentice Hall.

Nelson, J. (2010). Is Cirque du Soleil having a midlife crisis? Recuperado em 12 junho, 2010, de http://www.canadianbusiness.com/managing/strategy/article.jsp?content=20100423_143850_99 84.

Oatley, K., \& Jenkins, J. (1996) Understanding emotions. Cambridge: Blackwell Publishers.

Oliveira, S. L. O. (1997). Tratado de metodologia científica: projetos de pesquisas, TGI, TCC, monografia, dissertações e teses (2a ed.). São Paulo: Pioneira.

Oliveira, V. I. (1997). Inovação como estratégia de competitividade [CD-ROM]. Anais do Encontro da Associação Nacional de Pós-Graduação e Pesquisa em Administração, 21. Rio de Janeiro: ANPAD. 
Felipe Cavalcante de Almeida, Alyne Oliveira Vale \& Sérgio H. A. Cavalcante Forte

Peteraf, M. A. (1993). The cornerstones of competitive advantage: a resource-based view. Strategic Management Journal, 14(3), 179-191. http://dx.doi.org/10.1002/smj.4250140303

Prahalad, C. K., \& Hamel, G. (1990). The core competence of the corporation. Harvard Business Review, 68(3), 79-91.

Prahalad, C. K., \& Ramaswamy, V. (2000).Co-opting customer competence. Harvard Business Review, 78(1), 79-87.

Ramaswamy, V. (2005). Co-creating experiences with customers: new paradigm of value creation. The TMCT Journal of Management, 3(2), 6-14.

Rivera, E. B. B. R. (2008). Resource based view e o neo-institucionalismo na análise organizacional para a promoção da vantagem competitiva sustentável [CD-ROM]. Anais do Simpósio de Gestão da Inovação Tecnológica, 25. Rio de Janeiro: ANPAD.

Samara, B. S., \& Morsc, M. A. (2005). Comportamento do consumidor: conceitos e casos. São Paulo: Pretince Hall.

Santos, J. V. T. (1991). A construção da viagem inversa: ensaio sobre a investigação nas ciências sociais. Cadernos de Sociologia, 3(3), 55-88.

Santos, T., \& Prado, P. H. M. (2008). Emoção e regulação emocional no comportamento do consumidor [CD-ROM]. Anais do Encontro de Marketing, 3. Rio de Janeiro: ANPAD.

Vargas, E. R. (2002). Estratégia e inovação em serviços [CD-ROM]. Anais do Encontro da Associação Nacional de Pós-Graduação e Pesquisa em Administração, 26. Rio de Janeiro: ANPAD.

Vieira, M. M. F., \& Zouain, D. M. (Orgs.). (2006). Pesquisa qualitativa em administração (2a ed.). Rio de Janeiro: FGV.

Weick, K. E., \& Roberts, K. H. (1993). Collective mind in organizations: heedful inter-relating on flight decks. Administrative Science Quarterly, 38(3), 357-381.

http://dx.doi.org/10.2307/2393372

Wernerfelt, B. (1984). A resource-based view of the firm. Strategic Management Journal, 5(2), 171-180.

http://dx.doi.org/10.1002/smj.4250050207

Revista Ibero-Americana de Estratégia - RIAE, São Paulo, v. 9, n. 3, p. 174-201, set./dez. 2010. 
Andando na Corda Bamba? Análise da Fragilidade da Emoção como Vantagem Competitiva na Criação de Valor do Cirque du Soleil

Recebido: 08/09/2010

Aprovado: 20/11/2010

Revista Ibero-Americana de Estratégia - RIAE, São Paulo, v. 9, n. 1, p. 174-201, set./dez. 2010. 
Felipe Cavalcante de Almeida, Alyne Oliveira Vale \& Sérgio H. A. Cavalcante Forte

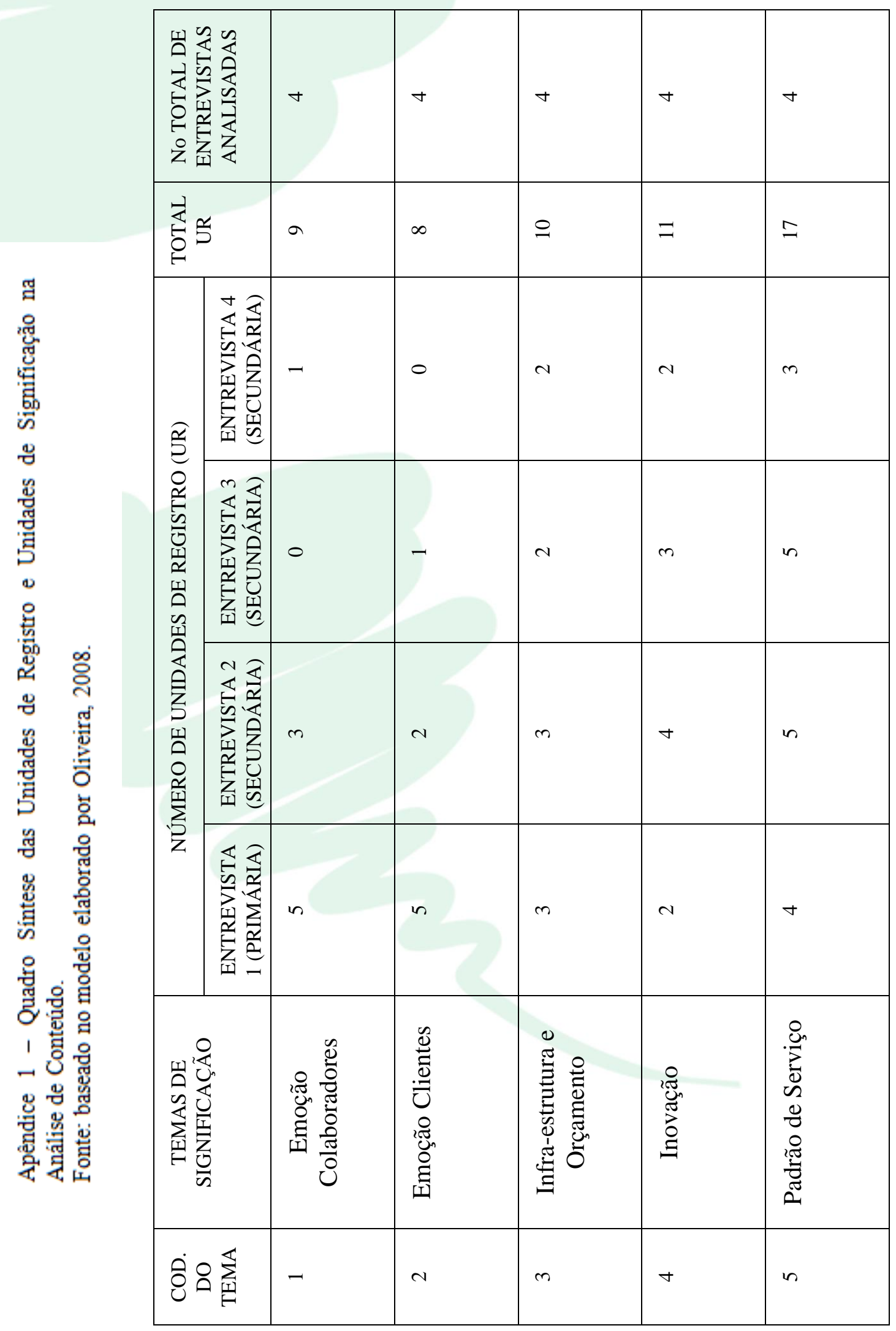

Revista Ibero-Americana de Estratégia - RIAE, São Paulo, v. 9, n. 3, p. 174-201, set./dez. 2010. 